\title{
Patient-provider communication about pregnancy and HIV among female sex workers living with HIV in Santo Domingo, Dominican Republic
}

\author{
Dana Cernigliaro ${ }^{1}$, Clare Barrington², Yeycy Donastorg ${ }^{3}$, Martha Perez ${ }^{3}$ and Deanna Kerrigan ${ }^{1,4^{*}}$
}

\begin{abstract}
Background: Health providers can play an important role in communication about pregnancy, particularly for women at increased risk for pregnancy complications, including female sex workers (FSWs) living with HIV. This study explored factors related to patient-provider communication about pregnancy among 253 FSWs living with HIV of reproductive age in Santo Domingo, Dominican Republic.

Methods: A cross-sectional design was employed including structured socio-behavioral surveys. Data were analyzed utilizing bivariate and multivariate logistic regression.

Results: Of the 253 FSWs living with HIV in this study, 95.7\% had been pregnant at least once (median: 4; IQR: 3,6), 28.0\% wanted more children and 36\% reported a pregnancy after HIV diagnosis. Over half of participants (58.0\%) reported having ever spoken to a health provider about pregnancy while living with HIV. Multivariate logistic regression found significant associations between having spoken to a health provider about HIV in pregnancy and a more positive perception of their provider (AOR: 2.0; 95\% Cl: 1.0, 2.5) and years since HIV diagnosis (AOR: 1.1; 95\% $\mathrm{Cl}$ : 1.0, 1.1). Participants were less likely to speak with a provider if they had a history of drug use (AOR: $0.4 ; 95 \% \mathrm{Cl}$ : $0.2,0.9$ ) or current alcohol use (AOR: $0.5 ; 95 \% \mathrm{Cl}: 0.3,0.9$ ).

Conclusion: Findings highlight the importance of non-judgmental and tailored provider-initiated conversations surrounding pregnancy. Future research is needed to better understand how and when pregnancy communication is initiated, as well as the content of clinical care conversations, to address the reproductive health of FSWs living with HIV.
\end{abstract}

Keywords: Sex workers, HIV, Pregnancy, Reproductive health, Patient-provider communication, Dominican Republic

\section{Background}

Pregnancy rates among women living with HIV have significantly increased over the last 10 years across geographic settings, giving increased salience to preconception conversations surrounding pregnancy $[1,2]$. Conversations surrounding pregnancy care and counseling by a health provider can address the increased risks that women living with HIV and their infants face, therefore leading to

\footnotetext{
* Correspondence: kerrigan@america.edu

1The Johns Hopkins Bloomberg School of Public Health, 624 N Broadway HH 257, Baltimore, MD 21205, USA

${ }^{4}$ Center on Health, Risk \& Society, American University, 4400 Massachusetts Avenue, Washington, DC, NW 20016, USA

Full list of author information is available at the end of the article
}

improved health outcomes [3-5]. For women living with HIV who desire more children, preconception care and counseling provides an opportunity to promote planned pregnancies, dispel fears about pregnancy and HIV, educate women on prevention of mother to child transmission of HIV (MTCT) through ART adherence and retention in care, and help ensure safe outcomes for both mother and child [5-8]. Further, for women who do not want to get pregnant, discussing pregnancy and family planning can prevent unwanted pregnancies and potential negative mental and physical health outcomes.

When conversations surrounding pregnancy do occur between women living with HIV and their health providers,

(c) The Author(s). 2019 Open Access This article is distributed under the terms of the Creative Commons Attribution 4.0 International License (http://creativecommons.org/licenses/by/4.0/), which permits unrestricted use, distribution, and reproduction in any medium, provided you give appropriate credit to the original author(s) and the source, provide a link to the Creative Commons license, and indicate if changes were made. The Creative Commons Public Domain Dedication waiver (http://creativecommons.org/publicdomain/zero/1.0/) applies to the data made available in this article, unless otherwise stated. 
they are frequently patient-initiated and occur after pregnancy $[6,8,9]$. Health care workers' methods of communication and their attitudes have been seen to influence proactive communication and personal decisions surrounding pregnancy and fertility among women living with HIV [10-12]. If women living with HIV perceive negative attitudes, stigma or discrimination about childbearing from their health provider, they are more likely to have negative attitudes themselves and may avoid discussing fertility $[12,13]$. In many settings, however, a majority of HIV-infected women of reproductive age have never discussed pregnancy and childbearing with their health providers, highlighting a clear gap in service provision [6-8].

Reasons for this gap and for the lack of pregnancy communication between health providers and women living with HIV can be seen from both the provider and patient perspective. From a patient perspective, women may be more concerned with competing priorities and more immediate concerns when seeing a health provider. Women may also feel stigmatized or judged due to their HIV infection or lack a sense of empowerment to discuss sexual health [13]. Even if women living with HIV feel that they can conceive with appropriate care, they may still feel societal stigma at having children, adding to difficulty in initiating the conversation [8]. Providers may be reluctant to discuss reproduction and fertility or may assume that women living with HIV do not want to become pregnant [13]. From a dual perspective, there may be lack of knowledge about pregnancy in HIV by either patient or provider, or a lack of defined provider roles if the patient is seeing multiple providers for care [13].

In addition to preconception communication surrounding pregnancy, challenges in communication have been seen to continue through care and treatment after pregnancy [14]. For example, patient-provider interactions during pregnancy related to ART initiation and adherence [12] have been found to include negative factors such as stigma and discrimination, a biomedicallyfocused conversation without addressing social factors [15] and power dynamics between patient-provider that affect a woman's ability to ask questions [16].

Within the body of research focused on patientprovider communication for women living with HIV, there has been limited attention to marginalized populations, such as female sex workers (FSWs). Globally, many FSWs have children and have been pregnant $[17,18]$. Similar to women living with HIV, FSWs face severe discrimination from health care workers and other barriers to care in different geographic settings [19-22]. At the same time, FSWs are at greater risk for a number of health concerns including HIV, other STIs, gender-based violence $[18,23,24]$ and complications associated with reproductive health, pregnancy and childbearing $[25,26]$.

The global burden HIV for FSWs is significant, with FSWs having approximately 13.5 greater odds of being HIV-infected than women in the general population in lower and middle-income countries [27]. Additionally, FSWs living with HIV are faced with multiple stigmatized identities. They are more likely to experience discrimination in health care settings, report feelings of social isolation once they learned their HIV sero-status, face refusal of medical care or fear of seeking services compared to FSWs not living with HIV [21]. Prior research has found that FSWs who desire children are more likely to have higher levels of HIV-related internalized stigma, a history of pregnancy loss and perceive that their partner has negative feeling about a pregnancy [28]. FSWs who become pregnant after HIV diagnosis are more likely to have ART interruption and have a more negative perception of their health provider [29]. Acknowledgement of the need for comprehensive and tailored prevention, care and treatment for this population is understood by the global community [22]. This paper aims to understand factors related to patient-provider communication about pregnancy among FSWs living with HIV in Santo Domingo, Dominican Republic (DR).

\section{Methods}

\section{Study context}

The current analysis is from baseline data of a longitudinal multi-level intervention study named Abriendo Puertas (Opening Doors). The aim of Abriendo Puertas was to assess the feasibility and initial effects of a multi-level intervention to promote engagement in and adherence to HIV care and foster preventive sexual health behaviors for FSW living with HIV through counseling, education, peer navigation, provider engagement and community mobilization [30]. Sex work is not illegal in the DR and organizations exist whose aim is to educate and empower FSWs. FSWs in the DR are disproportionately affected by HIV, with a prevalence estimated at $4.8 \%$, [23] as compared to $0.7 \%$ for the country [31].

\section{Study sample, collaborative partners and recruitment}

This study collaborated with partners in Santo Domingo to conduct formative research, including Movimiento de Mujeres Unidas, a sex worker rights group and Centro de Orientacion e Investigacion Integral, an HIV prevention organization and a local research unit. Study participants were recruited through convenience sampling techniques. Participants were identified through peer navigators at collaborating HIV clinics and through the navigator's community outreach, as well as through referrals by other study FSWs living with HIV in the study. FSWs were defined as women who report having exchanged sex 
for money in the last month. Eligibility criteria included being at least 18 years of age, spoke Spanish and reported HIV-infection, confirmed prior to enrollment by a HIV rapid test. Enrollment occurred from November 2012 to February 2013, resulting in a sample size of 268 FSWs living with HIV. Details of recruitment and study design have been described previously [28-30]. This analysis includes a subset of FSWs who were of reproductive age while living with HIV for a total of 253 FSWs living with HIV.

\section{Data collection}

This baseline socio-behavioral survey was conducted by trained Dominican field staff in Spanish within private offices of the HIV Vaccine Research Unit (HVRU) of the Instituto Dermatologico y Cirugia de la Piel Dr. Humberto Bogart Diaz (IDCP). Blood samples for HIV viral load were assessed at the Dominican National Reference Laboratory in Santo Domingo using polymerase chain reaction $(\mathrm{PCR})$ testing.

\section{Ethical consideration}

Oral consent was provided and participants were compensated 400 Dominican pesos (about \$10) for survey completion. Interviewers signed IRB approved consent forms indicating participant's verbal consent to both the survey and blood draw for the study. Approval was granted by the following Institutional Review Boards: Johns Hopkins Bloomberg School of Public Health, University of North Carolina and the Instituto Dermatologico y Cirugia de la Piel Dr. Humberto Bogart Diaz.

\section{Measures}

\section{Dependent variable}

The main outcome was assessed through the following question, "Have you and a health care provider ever talked about pregnancy in women living with HIV?" Response options were "yes" "no" "don't know" and "refuse to answer". All respondents answered either yes or no and therefore treated as a dichotomous variable.

Key independent variables: Selection of independent variables was guided though background literature and conceptual relevance. The main independent variable was perception of your main health provider, a scale from 1 to 4 that included eight questions, such as "You feel respected by your doctor" and "Your feel comfortable asking your doctor questions about your care". A higher score meant greater satisfaction with your health provider. Other independent variables included socio-demographic characteristics (age, civil status, education), risk behaviors (alcohol use, drug use ever), HIV characteristics (years since diagnosis, viral load), stigma scales (HIV related internalized stigma, sex work related internalized stigma) and sexual and reproductive health characteristics (number of pregnancies, contraception use, pregnant since diagnosis, attitudes about pregnancy and HIV, knowledge or MTCT, and a desire for more children).

\section{Aggregate measures}

Consistent condom use was an aggregate of three separate questions asking FSWs living with HIV if they: 1) ever had sex without a condom 2) had sex without a condom in the last 30 days and 3) had sex without a condom the last time they had sex. These questions were asked for 3 types of partners (regular partner, casual partner, client). If FSWs living with HIV answered that condoms were consistently used for each partner this was categorized as consistent condom use. Stigma scales included sex work and HIV-internalized stigma scales. Scales were developed using adapted measures from Berger et al., [32] Zelaya et al., [33, 34] and Baral et al., [35] and with guidance from Earnshaw's HIV Stigma Framework [36]. All stigma scales included options of 1 to 4 , with1 being the least amount of stigma and 4 the most stigma. Statements such as "Having HIV makes you feel like a bad person" or "You feel ashamed that you have HIV" among others were included in the HIV stigma scale, while the sex work stigma scale asked similar questions about sex work. Response options included: $1=$ totally disagree, $2=$ disagree, $3=$ agree, $4=$ totally agree, $88=$ don't know and $99=$ refuse to answer. All answers of "don't know" and "refuse to answer" responses were coded as 2.5 to maintain sample size but neutralize their weight. Standardization of directionality was ensured for all questions. The provider satisfaction scale, the primary independent variable, was adapted from the validated Patients Reactions Assessment scale [37] differed in that a higher score meant a greater satisfaction with their providers. Data reduction occurred through principal components analysis. Eigenvalues of $\geq 1$ were considered, along with scree plots and parallel factor analysis results, followed by a test of normality. Factors were rotated and if factor loadings were less than 0.4 and uniqueness was greater than 0.5 , the factors were dropped. Once items were chosen for removal, Cronbach alpha tests were conducted (see Table 1) in order to measure internal consistency of the final scale. When scales were finalized, the items included were averaged across participant to create each final variable.

\section{Data analysis}

Data was collected and uploaded into a secure SQL server database and converted to Stata version 11 for analysis. Exploratory analysis was conducted and any outliers or inconsistencies were checked against original data. T-tests or chi-square analysis, as appropriate, were used to explore associations between independent variables and the outcome. Bivariate logistic regression was 
Table 1 Stigma and provider scale characteristics

\begin{tabular}{lll}
\hline Scale name & Number of final items & Cronbach alpha score \\
\hline HIV related self-internalized stigma scale & 7 & 0.88 \\
Sex work related self/ internalized stigma scale & 12 & 0.91 \\
Provider satisfaction scale & 8 & 0.96
\end{tabular}

conducted to determine odds ratios and confidence intervals for each independent variable. Associations that were determined at a $0.10 p$-value level or less and guided by background literature and conceptual relevance were included in the model. The final model was built using multiple iterations through a traditional stepwise approach. After the addition of each variable the Akaike information criterion (AIC) was calculated for each nested model and log likelihood tests were assessed. The model with the most parsimonious fit- the lowest AIC value, together with low log likelihood values aided in the determination of the final model. Finally, a Hosmer-Lemeshow goodness of fit test was then conducted to determine the fit of the final model.

\section{Results}

\section{Descriptive characteristics}

The final sample size was 253 female sex workers living with HIV, with a median age of 35 years (interquartile range (IQR): 30,40$)$. Table 2 illustrates sociodemographic, behavioral, sexual health, HIV and stigma characteristics. Almost all women had some education (98.4\%), most at the primary level (61.3\%) and most were married or had a partner $(81.8 \%)$. The median age reported for first engaging in sex work was 18 years (IQR: $15,23)$ with a majority reporting they were under 20 years of age. Predominant sex work locations included establishment-based (e.g. disco, bar, hotel, billiard) or the street, however many indicated more than one location. A majority (59.7\%) reported never or rarely drinking alcohol. More than half (63.6\%) reported consistent condom use with all sexual partners. Number of years since HIV diagnosis was broad (mean: 6.0; range: $<1$ year, 30 years), however, $63.2 \%$ were diagnosed in the last 6 years.

\section{Reproductive health and pregnancy}

Reproductive health and service characteristics are illustrated in Table 3. Almost all of the women were pregnant at least once (95.7\%) and had children (93.3\%) with a median of 3 children (IQR: 2, 4). Many women reported at least one pregnancy since diagnosis $(36.0 \%)$, with a median of 4 pregnancies (IQR: 3,6). About $28.0 \%$ indicated a desire for (more) children. A high number of women (158/241) 65.6\%) reported a pregnancy that did not result in a live birth. Over half did not feel that it is good to get pregnant if you are living with HIV and desire more children (56.1\%). Barriers to care included feelings that lack of access to treatment and HIV care was a serious problem for FSWs (75.0\%), having ever had a fear of seeking health services due to HIV or sex work (44.4\%), confusion with provider communication about treatment $(31.9 \%)$ and fear that their provider may not keep their information private (30.0\%). Communication with a health provider occurred for more than half (57.9\%) and clear gaps in communication were seen for women in most need of this discussion. For example, gaps in communication occurred among women who had previously spoken to a healthcare provider about pregnancy in HIV-positive women and had been pregnant since HIV diagnosis $(56 / 146,38.6 \%)$, wanted more children $(36 / 146,24.7 \%)$ and those who felt it was not good to get pregnant if you are living with HIV $(83 / 146,56.4 \%)$.

\section{Associations with having spoken to a health provider about HIV and pregnancy}

Bivariate and multivariate regression analysis results are highlighted in Table 4. Bivariate regression analysis revealed associations at the 0.05 level of significance or less between female sex workers who had spoken to a health provider about pregnancy among women living with HIV and those reporting substance use (ever having used drugs (OR: 0.3; 95\% CI: $0.2,0.6)$ or current often/occasional alcohol use (OR: 0.5 ; 95\% CI: $0.3,0.8)$ ) and women with a better perception of their health provider (OR: 2.0; 95\% CI: $1.3,3.0)$. Both stigma scales had non-significant negative associations with the outcome, with association of HIV internalized stigma only marginally non-significant (OR:0.7; 95\% CI: 0.4, 1.1). Controlling for age, civil status and education, years living with HIV and number of times pregnant, the multivariate analysis uncovered a number of associations with having ever spoken to a health care provider about HIV and pregnancy at the 0.05 level of significance. Female sex workers living with HIV who had a conversation about HIV and pregnancy with their health provider were more likely to have a more positive perception of their health providers (AOR: 1.6; 95\% CI: 1.0, 2.5), less likely to have had alcohol use in the last 30 days (AOR: 0.5, 95\% CI: 0.3, 0.9) and are less likely to have a history of drug use (AOR: 0.4, 95\% CI: 0.2, 0.8). 
Table 2 Socio-demographic and health characteristics of FSWs living with HIV $(n=253)$

\begin{tabular}{|c|c|c|c|c|}
\hline Socio-demographic characteristics & $\mathrm{N}$ & Percent & Median (IQR) & Mean \pm SD \\
\hline Age & & & $35(30,40)$ & \\
\hline \multicolumn{5}{|l|}{ Civil status } \\
\hline Single/widowed or divorced no regular partner & 46 & 18.2 & & \\
\hline Married or have a partner & 207 & 81.8 & & \\
\hline Education (any) & 249 & 98.4 & & \\
\hline No education & 4 & 1.6 & & \\
\hline Primary education & 155 & 61.3 & & \\
\hline Secondary or tertiary & 94 & 32.2 & & \\
\hline \multicolumn{5}{|l|}{ Current Residence } \\
\hline Santo Domingo & 196 & 77.5 & & \\
\hline Other area & 57 & 22.5 & & \\
\hline \multicolumn{5}{|l|}{ Sex work and risk behavior characteristics } \\
\hline Age first engaged in sex work & & & $18(15,23)$ & \\
\hline Average price per salida (pesos) & & & & $886 \pm 534^{\mathrm{a}}$ \\
\hline Number of clients/wk. & & & $3(2,6)$ & \\
\hline \multicolumn{5}{|l|}{ Work Locations } \\
\hline Establishment & 155 & 59.7 & & \\
\hline The street & 140 & 55.3 & & \\
\hline Other (predominantly by calling) & 80 & 31.6 & & \\
\hline Any conflict with a sex partner in the last 6 months & 92 & 36.4 & & \\
\hline \multicolumn{5}{|l|}{ Alcohol use } \\
\hline Sometimes/often & 102 & 40.3 & & \\
\hline Rarely/never & 151 & 59.7 & & \\
\hline Drug use (ever) & 62 & 24.5 & & \\
\hline \multicolumn{5}{|l|}{ Sexual health and HIV care } \\
\hline Consistent condom use with all partners $(n=250)$ & 159 & 63.6 & & \\
\hline Permanent contraceptive procedure after diagnosis & 74 & 29.4 & & \\
\hline $\begin{array}{l}\text { Viral Load }(n=249) \\
\text { Undetectable }(<50 \text { copies/cc })\end{array}$ & 119 & 47.8 & & \\
\hline Detectable & 130 & 52.2 & & \\
\hline Current ARV use $(n=252)$ & 182 & 72.2 & & \\
\hline Years since HIV diagnosis & & & & $6.0 \pm 4.7$ \\
\hline \multicolumn{5}{|l|}{ Stigma and provider scales $(n=253)^{\mathrm{b}}$} \\
\hline HIV related self-internalized stigma scale (20) & & & & $2.4 \pm 0.6$ \\
\hline Sex work related self-internalized stigma scale (19) & & & & $2.4 \pm 0.6$ \\
\hline Perception of provider scale & & & & $3.2 \pm 0.6$ \\
\hline
\end{tabular}

a 870 pesos $\sim \$ 20$ b Stigma scales: 1 is the lowest amount of stigma and 4 the highest. Provider scale: a higher scale indicates better perception of provider

\section{Discussion}

This study aimed to understand factors related to communication with health providers among female sex workers living with HIV in the DR. Results highlight that while pregnancy and childbearing are prevalent in these women's lives, there are clear barriers to provider communication about pregnancy, as has been documented previously in other studies of women living with $\operatorname{HIV}[6,8]$.
Many FSWs living with HIV who have been pregnant since diagnosis and who want more children have never spoken to a provider about pregnancy. Pregnancy, pregnancy desire, and having children are prevalent among these women. However, this population is at high risk for pregnancy and postpartum related health issues and therefore is most in need for constructive, non-judgmental conversations with their health provider. 
Table 3 Reproductive health and health service characteristics among FSWs living with HIV $(n=253)$

\begin{tabular}{|c|c|c|c|c|}
\hline Reproductive health and health service characteristics & $\mathrm{N}$ & Percent & Median (IQR) & Mean \pm SD \\
\hline Currently have children & 236 & 93.3 & & \\
\hline Number of children $(n=236)$ & & & $3(2,4)$ & \\
\hline Have ever been pregnant in lifetime & 242 & 95.7 & & \\
\hline Number of times pregnant $(n=242)$ & & & $4(3,6)$ & \\
\hline At least one pregnancy loss $(n=241)$ & 158 & 65.6 & & \\
\hline Have been pregnant since HIV diagnosis & 91 & 36.0 & & \\
\hline Number of times pregnant $(n=91)$ & & & & $1.6 \pm 0.9$ \\
\hline At least one pregnancy loss since diagnosis $(n=91)$ & 33 & 27.7 & & \\
\hline Desire to have more children (yes or maybe) & 70 & 28.3 & & \\
\hline Number of children desired $(n=68)$ & & & & $1.6 \pm 0.9$ \\
\hline Currently/possibly pregnant & 8 & 3.2 & & \\
\hline Do not feel that if an HIV positive woman wants to get pregnant she should & 142 & 56.1 & & \\
\hline Knows that ARTs can reduce the risk of MTCT & 192 & 75.9 & & \\
\hline Feels health providers are supportive of pregnancy in women living with HIV & 191 & 75.5 & & \\
\hline \multicolumn{5}{|l|}{ Services and health care } \\
\hline Feel that a lack of access to treatment and HIV care is a serious problem for SW & 185 & 75.2 & & \\
\hline Have ever been afraid to seek health services due to HIV or sex work & 112 & 44.4 & & \\
\hline Worry that people will find out my HIV status if I attend the health clinic $(n=252)$ & 81 & 32.1 & & \\
\hline When your doctor gives information about treatment you come away feeling confused & 73 & 31.9 & & \\
\hline Feels that health providers might not keep information private & 75 & 28.0 & & \\
\hline \multicolumn{5}{|l|}{ Reproductive health access to care and services } \\
\hline Have ever spoken to a healthcare provider about pregnancy in HIV positive women $(n=252)$ & 146 & 57.9 & & \\
\hline And have been pregnant since HIV diagnosis & 56 & 38.6 & & \\
\hline And would like/might like another child & 36 & 24.7 & & \\
\hline And who disagree that it is good to get pregnant if you are HIV positive & 83 & 56.4 & & \\
\hline Have been pregnant since diagnosis without discussing pregnancy $(91-56=35 ; 35 / 91)$ & 35 & 38.4 & & \\
\hline Would like (more) children and have not discussed pregnancy $(70-36=34 ; 34 / 70)$ & 34 & 48.6 & & \\
\hline Did not use any method to prevent pregnancy in the last $6 \mathrm{M}(n=252)$ & 45 & 17.9 & & \\
\hline And do not want more children & 27 & 60.0 & & \\
\hline
\end{tabular}

Substance use (both current alcohol use and history of drug use) was a significant deterrent to provider communication about pregnancy. Substance use has also been associated with ART interruption, STI diagnosis and having detectable viral load for women living with HIV [30, 38]. Since substance use is also a stigmatized behavior, a population that is dealing with multiple stigmatized identities may avoid discussing pregnancy for fear of judgment. It is important to consider how substance use may further inhibit self-initiated or provider-initiated communication about pregnancy based on explicit and implicit biases among female sex workers living with HIV who are also substance users.

We also found that female sex workers living with HIV who had a more positive perception of their providers were significantly more likely to have spoken to a health provider about pregnancy, possibly because they felt that they will not be judged by their provider about their reproductive health decisions. Provider verbal and non-verbal attitudes have been seen to be influential on the desire to discuss pregnancy and personal decisionmaking surrounding pregnancy among women living with HIV $[10-12,39]$. For these women who have multiple reproductive health concerns and who face multiple barriers to care, the need for non-discriminatory care and counseling from healthcare and HIV clinical providers is critical for both maternal and child health.

Lack of patient-provider communication about pregnancy has been seen among women living with HIV in other settings $[6-8,40]$, however FSWs may be at greater risk pregnancy related complications $[25,26]$. The lack of patient-provider communication surrounding pregnancy in this study is concerning due to the high reported number of lifetime pregnancies, number of 
Table 4 Bivariate and multivariate logistic regression analysis for having spoken to a health provider about pregnancy among FSWs living with HIV $(n=252)$

\begin{tabular}{|c|c|c|c|c|}
\hline Sociodemographics & OR & $95 \% \mathrm{Cl}$ & AOR & $95 \% \mathrm{Cl}$ \\
\hline Age & 1.0 & $1.0,1.0$ & 1.0 & $0.9,1.0$ \\
\hline Civil status (ref: has partner) & 0.7 & $0.4,1.3$ & 0.9 & $0.4,1.7$ \\
\hline Education (ref: secondary/tertiary education) & 1.6 & $0.9,2.7$ & 1.3 & $0.7,2.3$ \\
\hline \multicolumn{5}{|l|}{ Risk behaviors and HIV characteristics } \\
\hline Alcohol use (last 30 days) & $0.5^{* *}$ & $0.3,0.8$ & $0.5^{*}$ & $0.3,0.9$ \\
\hline Drug use ever & $0.3^{* * *}$ & $0.2,0.6$ & $0.4^{*}$ & $0.2,0.8$ \\
\hline Years since HIV diagnosis & $1.1^{*}$ & $1.0,1.1$ & $1.1^{*}$ & $1.0,1.1$ \\
\hline Viral load $(n=248)$ & 0.6 & $0.4,1.0$ & & \\
\hline \multicolumn{5}{|l|}{ Sexual and reproductive health characteristics } \\
\hline Number of times pregnant & 0.9 & $0.8,1.0$ & 0.9 & $0.8,1.1$ \\
\hline No contraception in the last 6 months & 0.8 & $0.4,1.5$ & & \\
\hline Have been pregnant since HIV diagnosis & 1.3 & $0.8,2.1$ & & \\
\hline If an woman with HIV wants to get pregnant she should try & 0.9 & $0.5,1.5$ & & \\
\hline Knows that ART during pregnancy can prevent MTCT & 1.1 & $0.6,2$ & & \\
\hline Desire more children & 0.7 & $0.4,1.2$ & & \\
\hline \multicolumn{5}{|l|}{ Stigma and support } \\
\hline Perception of provider scale & $2.0^{* *}$ & $1.3,3.0$ & $1.6^{*}$ & $1.0,2.5$ \\
\hline HIV related internalized stigma scale & 0.7 & $0.4,1.1$ & & \\
\hline Sex work related internalized stigma scale & 0.9 & $0.6,1.4$ & & \\
\hline
\end{tabular}

${ }^{*} p \leq 0.05,{ }^{* *} p \leq 0.01,{ }^{* * *} p \leq 0.001$

children and pregnancies that did not result in live births. These women were all of reproductive age when diagnosed with HIV and had seen a health provider at least once, highlighting missed opportunities for education and tailored care. Many FSWs living with HIV reported not using any contraceptive methods to prevent pregnancy in the last 6 months and reported not wanting more children, highlighting an unmet need for conversations surrounding family planning. Additionally, studies have found that female sex workers living with HIV who want children are more likely to have HIV-related internalized stigma and a history of pregnancy loss, [28] while those who have been pregnant after HIV diagnosis are more likely to have a negative perception of their health provider and have ART interruption [29].

We did not find a significant association between HIV or sex work internalized stigma and speaking to a provider about pregnancy in this study. Many female sex workers may not disclose their sex work to providers for fear of stigma or judgment, [19-22] which may explain the lack of association with the sex work related internalized stigma scale. Other studies have also found influences between HIV related stigma and patient-provider communication $[8,13]$ and the desire for more children [29].

Patient-provider communication regarding reproductive health and pregnancy is essential on multiple levels- to reduce stigma, to tailor care, and to provide appropriate support for women living with HIV. While the majority of female sex workers living with HIV had spoken to a health care provider about pregnancy and HIV, it is of concern that numbers were lower among HIV-positive women who had been pregnant since HIV diagnosis, who wanted more children and who had negative perceptions of pregnancy and HIV. Further, the fact that most women felt that lack of access to treatment and care was a problem for sex workers and many have been afraid to seek services due to HIV or sex work- further research is needed to explore dynamics between female sex workers living with HIV and health providers.

Proper preconception conversations with providers can dispel anxiety, encourage adherence and ultimately improve maternal and child health as well as help avoid unwanted pregnancies and prevent unsafe abortion [5]. In a country that where there are strict legal barriers to safe abortion, [41] a history of high maternal and infant mortality rates [42] and a history of questionable maternity wards practices, [43] understanding barriers to patient-provider communication is even more salient for these women, who face multiple stigmatized identities.

There are several limitations that should be discussed with regard to this study. First this study is cross-sectional in nature and therefore only captures participant information at one point in time. There may be issues with selfreport or recall bias for many questions and a level of 
social desirability bias for issues surrounding health care or behavior. Future studies should focus on nuances of patient-provider communications surrounding pregnancy among these women including whether conversations are patient or provider initiated or if these conversations occur pre or post conception. Qualitative studies would also be helpful to further understand the context and details of these conversations. With these limitations and gaps in mind, this study did highlight important factors related to patient-provider communication about pregnancy for a key population that is at high risk for unintended pregnancy, MTCT and health complications during pregnancy. Interventions with health providers are needed to ensure safe and respectful conversations surrounding family planning for a population that is in significant need of comprehensive reproductive health services.

\section{Conclusions}

Female sex workers living with HIV face a number of challenges and barriers to care for reproductive health. FSWs with a history or current substance use may be less likely to have conversations about HIV and pregnancy with their provider, but they are at greater risk for pregnancy complications. Non-judgmental providerinitiated conversations surrounding pregnancy and family planning are essential for a safe pregnancy outcomes. Health providers sensitized to these concerns can play a critical role in promoting the health and well-being of FSWs living with HIV and their families. Tailored services and interventions that address multiple levels of risk for FSWs living with HIV are crucial, as this population faces unique health concerns and barriers to care.

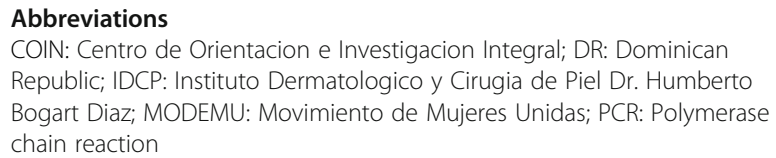

\section{Acknowledgements}

We thank the participants and study staff for their time and dedication to this effort.

\section{Authors' contributions}

DC analysis and manuscript writing; YD and MP oversight of fieldwork and manuscript review; CB and DK design and oversight of patent study and manuscript review. All authors have read and approved the manuscript.

\section{Funding}

This Research to Prevention (R2P) project was supported by USAID Project SEARCH, Task Order No. 2, funded by the US Agency for International Development under Contract No. GHH-I-02-07-00032-00, beginning 30 enter for AIDS Research, 1P30AI094189, provided additional support. The funding agency was not involved in the data collection, analysis or interpretation for this study.

\section{Availability of data and materials}

Data available upon request from Dr. Deanna Kerrigan, American University, 4400 Massachusetts Avenue, Washington DC NW 20016. USA. Email: kerrigan@american.edu.

\section{Ethics approval and consent to participate}

The Institutional Review Boards of the Johns Hopkins Bloomberg School of Public Health, the University of North Carolina and the Instituto Dermatologico y Cirugia de la Piel Dr. Humberto Bogart Diaz in the Dominican Republic approved the study including the oral consent form utilized in the study. Participants provided oral rather than written consent to protect the confidentiality of a highly stigmatized population group.

Consent for publication

Not applicable.

\section{Competing interests}

The authors declare that they have no competing interests.

\section{Author details}

${ }^{1}$ The Johns Hopkins Bloomberg School of Public Health, 624 N Broadway HH 257, Baltimore, MD 21205, USA. ${ }^{2}$ The University of North Carolina Gillings School of Global Public Health, Rosenau Hall 319B, CB\#7440, Chapel Hill, NC 27599, USA. ${ }^{3}$ Instituto Dermatologico y Cirugia de la Piel, Albert Thomas, 66, Santo Domingo, Dominican Republic. ${ }^{4}$ Center on Health, Risk \& Society, American University, 4400 Massachusetts Avenue, Washington, DC, NW 20016, USA

Received: 23 August 2018 Accepted: 28 August 2019

Published online: 21 November 2019

References

1. Westreich D, Maskew M, Rubel D, MacDonald P, Jaffray I, Majuba P. Incidence of pregnancy after initiation of antiretroviral therapy in South Africa: a retrospective clinical cohort analysis. Infect Dis Obstet Gynecol. 2012;2012:917059 Available from: http://www.pubmedcentral.nih.gov/ articlerender.fcgi?artid=3388336\&tool=pmcentrez\&rendertype=abstract.

2. Huntington SE, Thorne C, Bansi LK, Anderson J, Newell M-L, Taylor GP, et al. Predictors of pregnancy and changes in pregnancy incidence among HIVpositive women accessing HIV clinical care. AIDS. 2013;27(1):95-103 Available from: http://www.pubmedcentral.nih.gov/articlerender.fcgi?artid= 3495056\&tool=pmcentrez\&rendertype=abstract.

3. Brocklehurst $P$, French $R$. The association between maternal HIV infection and perinatal outcome: a systematic review of the literature and metaanalysis. Br J Obstet Gynaecol. 1998;105(8):836-48 Available from: http:// www.ncbi.nlm.nih.gov/pubmed/9746375.

4. Kreitchmann R, Harris DR, Kakehasi F, Haberer JE, Cahn P, Losso M, et al. Antiretroviral adherence during pregnancy and postpartum in Latin America. AIDS Patient Care STDs. 2012;26(8):486-95 Available from: http:// www.pubmedcentral.nih.gov/articlerender.fcgi?artid=3462409\&tool= pmcentrez\&rendertype=abstract.

5. Steiner RJ, Sarah FK, Dariotis JK. Engaging HIV care providers in conversations with their reproductive-age patients about fertility desires and intentions: a historical review of the HIV epidemic in the United States. Am J Public Health. 2013;103(8):1357-66.

6. Finocchario-Kessler S, Dariotis JK, Sweat MD, Trent ME, Keller JM, Hafeez Q, et al. Do HIV-infected women want to discuss reproductive plans with providers, and are those conversations occurring? AIDS Patient Care STDs. 2010;24(5):317-23.

7. Schwartz SR, Mehta SH, Taha TE, Reeves HV, et al. High pregnancy intentions and missed opportunities for patient-provider communication about fertility in a south African cohort of HIV-positive women on antiretroviral therapy. AIDS Behav. 2012;16(1):69-78.

8. Squires $K E$, Hodder SL, Feinberg J, Bridge DA, Abrams S, Storfer SP, et al, Health needs of HIV-infected women in the United States: insights from the women living positive survey. AIDS Patient Care STDs. 2011;25(5):279-85.

9. Finocchario-Kessler S, Mabachi N, Dariotis JK, Anderson J, Goggin K, Sweat M. "We Weren't using condoms because we were trying to conceive": the need for reproductive counseling for HIV-positive women in clinical care. AIDS Patient Care STDs. 2012;26(11):700-7.

10. Nduna M, Farlane L. Women living with HIV in South Africa and their concerns about fertility. AIDS Behav. 2009;13(1):62-5.

11. Nattabi B, Li J, Thompson SC, Orach CG, Earnest J. A systematic review of factors influencing fertility desires and intentions among people living with HIV/AIDS: implications for policy and service delivery. AIDS Behav. 2009:13(5): 949-68 Available from: http://www.ncbi.nlm.nih.gov/pubmed/19330443. 
12. Sofolahan YA, Airhihenbuwa CO. Cultural expectations and reproductive desires: experiences of south African women living with HIV/AIDS (WLHA) Health Care Women Int. 2013;34(3-4):263-80.

13. Hoyt MJ, Storm DS, Aaron E, Anderson J. Preconception and contraceptive care for women living with HIV. Infect Dis Obstet Gynecol. 2012;2012:604183.

14. Ferguson L, Grant AD, Watson-Jones D, Kahawita T, Ong'ech JO, Ross DA. Linking women who test HIV-positive in pregnancy-related services to longterm HIV care and treatment services: a systematic review. Trop Med Int Health. 2012;17(5):564-80.

15. Levy JM. Women's expectations of treatment and care after an antenatal HIV diagnosis in Lilongwe, Malawi. Reprod Health Matters. 2009;17(33):152-61.

16. Gruskin S, Firestone R, MacCarthy S, Ferguson L. HIV and pregnancy intentions: do services adequately respond to women's needs? Am J Public Health. 2008;98(10):1746-50.

17. Decker MR, Yam EA, Wirtz AL, Baral SD, Peryshkina A, Mogilnyi V, et al. Induced abortion, contraceptive use, and dual protection among female sex workers in Moscow, Russia. Int J Gynaecol Obstet. 2013;120(1):27-31 Available from: http://www.pubmedcentral.nih.gov/articlerender.fcgi?artid= 3529991\&tool=pmcentrez\&rendertype=abstract.

18. Wayal S, Cowan F, Warner P, Copas A, Mabey D, Shahmanesh M. Contraceptive practices, sexual and reproductive health needs of HIV-positive and negative female sex workers in Goa, India. Sex Transm Infect. 2011;87(1):58-64 Available from: http://www.ncbi.nlm.nih.gov/pubmed/20980465.

19. Lazarus L, Deering KN, Nabess R, Gibson K, Tyndall MW, Shannon K. Occupational stigma as a primary barrier to health care for street-based sex workers in Canada. Cult Health Sex. 2012;14(2):139-50.

20. Scambler G, Paoli F. Health work, female sex workers and HIV/AIDS: global and local dimensions of stigma and deviance as barriers to effective interventions. Soc Sci Med. 2008;66(8):1848-62.

21. King EJ, Maman S, Bowling JM, Moracco KE, Dudina V. The influence of stigma and discrimination on female sex workers' access to HIV services in St. Petersburg, Russia. AIDS Behav. 2013;17(8):2597-603 Available from: http://www.pubmedcentral.nih.gov/articlerender.fcgi?artid=3868674\&tool= pmcentrez\&rendertype=abstract.

22. United Nations. Joint United Nations Programme on HIV (UNAIDS). Geneva: UNAIDS guidance note on HIV and sex work; 2009.

23. Kerrigan D, Wirtz A, Baral S, N'Jie N, Stanciole A, Butler J, et al. The Global HIV Epidemics among Sex Workers. Washington, D.C: World Bank Publications; 2012. Available from: https://books.google.com/books?hl=en\&lr=\&id=f60h4 OyZu_QC\&pgis=1

24. MacCarthy S, Rasanathan JJK, Ferguson L, Gruskin S. The pregnancy decisions of HIV-positive women: the state of knowledge and way forward. Reprod Health Matters. 2012;20(39 Suppl):119-40 Available from: http:// www.ncbi.nlm.nih.gov/pubmed/23177686.

25. Chacham AS, Diniz SG, Maia MB, Galati AF, Mirim LA. Sexual and reproductive health needs of sex workers: two feminist projects in Brazil. Reprod Health Matters. 2007;15(29):108-18.

26. Decker MR, McCauley HL, Phuengsamran D, Janyam S, Silverman JG. Sex trafficking, sexual risk, sexually transmitted infection and reproductive health among female sex workers in Thailand. J Epidemiol Community Health. 2011;65(4):334-9.

27. Baral S, Beyrer C, Muessig K, Poteat T, Wirtz AL, Decker MR, et al. Burden of HIV among female sex workers in low-income and middle-income countries: a systematic review and meta-analysis. Lancet Infect Dis. 2012;12(7):538-49 Available from: http://www.ncbi.nlm.nih.gov/pubmed/22424777.

28. Cernigliaro D, Barrington C, Perez M, Donastorg Y, Kerrigan D. Factors related to fertility desire among female sex workers living with HIV in the Dominican Republic. BMC Womens Health. 2018;18:117. https:/doi.org/10.1186/s12905-018-0613-1.

29. Cernigliaro D, Barrington C, Perez M, Donastorg Y, Kerrigan D. Factors related to pregnancy among female sex workers living with HIV in the Dominican Republic. AIDS Behav. 2016;20:2346. https://doi.org/10.1007/s10461-016-1422-x.

30. Donastorg Y, Barrington C, Perez M, Kerrigan D. Abriendo Puertas: baseline findings from an integrated intervention to promote prevention, treatment and care among FSW living with HIV in the Dominican Republic. PLoS One. 2014;9(2):e88157 Available from: http://www.pubmedcentral.nih.gov/ articlerender.fcgi?artid=3925113\&tool=pmcentrez\&rendertype=abstract.

31. UNAIDS. Global report: UNAIDS report on the global AIDS epidemic (2010).

32. Berger BE, Ferrans CE, Lashley FR. Measuring stigma in people with HIV: psychometric assessment of the HIV stigma scale. Res Nurs Health. 2001;24(6): 518-29 Available from: http://www.ncbi.nlm.nih.gov/pubmed/11746080.
33. Zelaya CE, Sivaram S, Johnson SC, Srikrishnan AK, Solomon S, Celentano DD. HIV/AIDS stigma: reliability and validity of a new measurement instrument in Chennai, India. AIDS Behav. 2008;12(5):781-8 Available from: http://www. ncbi.nlm.nih.gov/pubmed/18030613.

34. Zelaya CE, Sivaram S, Johnson SC, Srikrishnan AK, Suniti S, Celentano DD. Measurement of self, experienced, and perceived HIV/AIDS stigma using parallel scales in Chennai, India. AIDS Care. 2012;24(7):846-55.

35. Baral S, Adams D, Lebona J, Kaibe B, Letsie P, Tshehlo R, et al. A crosssectional assessment of population demographics, HIV risks and human rights contexts among men who have sex with men in Lesotho. J Int AIDS Soc. 2011;14:36 Available from: http://www.pubmedcentral.nih.gov/ articlerender.fcgi?artid=3146892\&tool=pmcentrez\&rendertype=abstract.

36. Earnshaw VA, Smith LR, Chaudoir SR, Amico KR, Copenhaver MM. HIV stigma mechanisms and well-being among PLWH: a test of the HIV stigma framework. AIDS Behav. 2013;17(5):1785-95 Available from: http://www. pubmedcentral.nih.gov/articlerender.fcgi?artid=3664141\&tool= pmcentrez\&rendertype=abstract.

37. Galassi JP, Schanberg R, Ware WB. The patient reactions assessment: a brief measure of the quality of the patient-provider medical relationship. Psychol Assess. 1992;4(3):346.

38. Zullinger R, Barrington C, Donastorg Y, Perez M, Kerrigan D. High drop-off along the HIV care continuum and ART interruption among female sex Workers in the Dominican Republic. J Acquir Immune Defic Syndr. 2015;69(2):216-22.

39. Harries J, Cooper D, Myer L, Bracken H, Zweigenthal V, Orner P. Policy maker and health care provider perspectives on reproductive decision-making amongst HIVinfected individuals in South Africa. BMC Public Health. 2007;7:282.

40. Mindry D, Wagner G, Lake J, Smith A, Linnemayr S, Quinn M, et al. Fertility desires among HIV-infected men and women in Los Angeles County: client needs and provider perspectives. Matern Child Health J. 2013;17(4):593-600.

41. United Nations. Department of Economic and Social Affairs Population Division. World abortion policies 2013.

42. World Health Organization, UNICEF. Trends in maternal mortality: 1990 to 2013: Estimates by WHO, UNICEF, UNFPA, the World Bank and the United Nations Population Division: Executive summary. 2014.

43. Proujansky AE. A Dominican maternity ward. Am J Nurs. 2008;108(12):40-3.

\section{Publisher's Note}

Springer Nature remains neutral with regard to jurisdictional claims in published maps and institutional affiliations.

Ready to submit your research? Choose BMC and benefit from:

- fast, convenient online submission

- thorough peer review by experienced researchers in your field

- rapid publication on acceptance

- support for research data, including large and complex data types

- gold Open Access which fosters wider collaboration and increased citations

- maximum visibility for your research: over $100 \mathrm{M}$ website views per year

At BMC, research is always in progress.

Learn more biomedcentral.com/submissions 